\title{
An Analysis of the Legal Framework Governing Prosecution of Traffickers and Victim Protection in Central Asian Countries
}

\section{Katerina Badikova *}

Slavery, along with other institutions and practices similar to slavery, has a long history of existence in Central Asia. These traditions were practiced during ancient times and the Middle Ages, and many of them continued to exist, albeit illegally, under the Soviet regime. In fact, the penal codes of the Soviet Socialist Republics of Central Asia included articles on the abduction of individuals, illegal detention, rape, forced marriage, marriage with more than one person, and sexual relations with a minor. Such acts were legally punishable in the Turkmen, Tajik, Kazakh, Kyrgyz and Uzbek Soviet republics. However, the observance of some traditions similar to slavery persisted, and the majority of the population continued to participate in some of these traditions, even under the risk of criminal prosecution. These traditional practices included such rituals as payment of kalym for the bride and arranged marriages. ${ }^{1}$ Bride kidnapping rituals were also widespread. At the time, it was impossible to prosecute anyone on charges of human trafficking, because as a phenomenon or a legal concept it was generally unknown, and therefore was not addressed in the criminal legislation.

In the early 1990s, the newly independent republics of the former Soviet Union tried to amend the legislation inherited from the Soviet era, adapting it to the new social and economic conditions of independence. However, amended Soviet laws were still inadequate in reflecting the emerging social realities in Central Asian countries and therefore, by the middle of the decade, the governments introduced a set of new legislation that included new penal codes, codes on criminal procedures (investigation and prosecution), codes on administrative misdemeanors, civil codes, codes of civil trial procedures, tax codes, and customs codes.

These new and improved legal codes more or less corresponded to the new conditions of life in the independent Central Asian republics, but further development demonstrated that in some countries the new legislation reflected the economic and social realities and met the needs of society better than in others. In Kazakhstan and Kyrgyzstan, for example, the new legal regime facilitated the development of a free-market economy, in spite of weak enforcement of some laws, high levels of bureaucratic procedure, and corruption, all of which hindered small and medium-sized businesses from developing rapidly. In Uzbekistan, agriculture and heavy industry continued to be controlled by the state, and the development of a small-business sector was curtailed by high taxes and strict government control. The government in Turkmenistan took control over all sectors of the economy. In Tajikistan, the nation's economic development was

Katerina Badikova is the Regional Counter-trafficking Program Officer for Central Asia, International Organization for Migration, Almaty, Kazakhstan. Opinions expressed in this article are those of the author and do not necessarily reflect the views of IOM.

1 Kalym is a traditional form of "bride-price," or a payment made by a man or his parents to the parents of the woman he wishes to marry. 
seriously impeded by civil wars that plagued the country during the mid-1990s. As a result, the differences in the levels of economic, social, and political development in the five countries became more and more obvious. In recent years, Kazakhstan has demonstrated stability and progress in its economy, especially in comparison with its neighbors Kyrgyzstan and Uzbekistan. At the same time, much significant commercial activity operated under conditions of a shadow economy, especially in Uzbekistan, whose high income taxes forced many people to seek unofficial modes of employment. This situation has created the conditions for organized criminal activities in the region in general, and for the successful development of human trafficking networks and structures in particular. In this context, human trafficking has become one of the most profitable economic activities in Central Asia, along with illicit drug trafficking and other kinds of organized crime.

The main forms of human trafficking that have been seen up to this point in Central Asia are trafficking for labor and sexual exploitation. Men are most vulnerable to becoming victims of the first form, while women and under-age girls are at the highest risk for the second.

Central Asia is a source, transit, and destination region for trafficking in persons. During the period from September 2003 to May 2005, the International Organization for Migration (IOM) registered 370 victims of trafficking - 66 male and 304 femalewho were trafficked from, through, and within Central Asia for sexual and labor exploitation. Among them, 292 persons were sent abroad from nations in Central Asia, and 44 were trafficked from one country to another within the region. There were also 34 victims of in-country trafficking registered.

The registered cases were divided along gender lines, with the majority being young women who were mainly trafficked to the United Arab Emirates, Turkey, Israel, South Korea, Greece, Thailand, Malaysia, and, more rarely, Western Europe. Incidents of internal trafficking cases involving people being brought from provincial centers to larger cities and to Astana, the new capital of Kazakhstan, are on the rise as well. However, it is difficult to calculate the actual total number of trafficking cases, due to deep social misgivings that confuse the phenomenon of human trafficking for purposes of sexual exploitation with voluntary prostitution. This stigma - along with maltreatment of trafficking victims by the authorities and the lack of any widespread public understanding of human trafficking as an issue of human rights abuse-discourages victims from reporting the crime or relating their experience, even to their closest friends and relatives. Moreover, law enforcement often fails to recognize trafficking cases as such if the victim has not been subjected to physical abuse, but rather is coerced into an exploitative situation through psychological pressure. Therefore, many trafficking cases go uncounted.

In addition to trafficking of young women from Central Asia for sexual exploitation abroad, information collected by telephone hotlines dedicated to human trafficking has revealed cases of young and middle-aged men being recruited for labor in slavery-like 
conditions in other states. ${ }^{2}$ Furthermore, cases of Uzbek, Kyrgyz, and Tajik girls being trafficked to Kazakhstan have been reported, as well as cases of the existence of unacceptable working conditions for Uzbek and Kyrgyz workers on tobacco and cotton plantations in southern parts of Kazakhstan and construction sites all over the country.

Central Asian traffickers establish connections with each other and form networks with the criminals who exploit victims in the countries of destination. Central Asian countries, especially Kazakhstan and Kyrgyzstan, also serve as transit territories. A trafficking victim recruited in Uzbekistan may leave for the United Arab Emirates with a false Kyrgyz passport from an airport in Kazakhstan. ${ }^{3}$ Many Tajik and Uzbek labor migrants who are subjected to severe exploitation in Russia cross Kazakhstan on their way from their native countries to their destination.

Despite some visible progress in adopting legislation criminalizing human trafficking, the official criminal statistics from Central Asia reflect that few prosecutions have taken place. In 2004, Kyrgyzstan and Tajikistan passed amendments that included an article on "Trafficking in Persons" into their penal codes. In 2003, Kazakhstan strengthened the law that punishes recruitment of individuals for sexual and other exploitation, and developed a number of amendments to other laws in order to bolster victim protection mechanisms and to improve the capacity of law enforcement to prosecute the crime of trafficking. These amendments were presented to the parliament in May 2005. Uzbekistan has not yet passed any counter-trafficking legislation, but has been trying to prosecute traffickers relying on the articles of the penal code that punish recruitment for exploitation and pimping. In Turkmenistan, the government agreed to participate in a workshop on the prevention of human trafficking in 2005, which can be viewed as a positive development for a country where human trafficking has never before been treated as a politically acceptable term or a relevant problem for the state.

Within the framework of existing legislation, it is difficult to prosecute all those involved in the Central Asian trafficking network (from recruiters to exploiters to corrupt officials). Usually, law enforcement agencies may only charge criminals on separate charges individually; it is difficult to prosecute a network. Active legislation in the sphere of social protection also provides little in terms of steps to aid in the reintegration and rehabilitation of victims.

According to the "Protocol to Prevent, Suppress, and Punish Trafficking in Persons, Especially Women and Children," which is a supplement to the UN Convention Against Transnational Crime, the crime of human trafficking involves numerous aspects, including recruitment, facilitation of dependency, and exploitation. The protocol urges states to establish human trafficking as a criminal offense under their national legisla-

2 The IOM, in close cooperation with its partner NGOs, started establishing counter-trafficking hotlines in Central Asia in 2001. Currently, NGOs operate twelve hotlines in Kazakhstan, eight in Tajikistan, and ten in Uzbekistan. During the period from September 2003 to May 2005 , the hotlines handled over 40,000 phone calls.

3 Presentation by the representatives of the Committee for National Security of the Republic of Kazakhstan at an IOM workshop for prosecutors and investigators, Medeo/Almaty, April 2003. 
tions and introduce measures that would uphold protection of victim's rights and recognize their special status. However, at the present moment-despite recommendations from national and international legal experts - the criminal codes of Kazakhstan and Uzbekistan still lack an article that addresses "human trafficking" as a specific and autonomous crime.

The UN Convention Against Transnational Organized Crime (the so-called UNTOC Convention) was signed by Kazakhstan, Kyrgyzstan, Tajikistan, and Uzbekistan, and was ratified - along with its counter-trafficking supplementary protocol-by Kyrgyzstan (2004) and Tajikistan (2005). After the ratifications, the two countries made amendments to their national legislation, and now trafficking in persons is punishable as a specific crime according to the penal codes of Kyrgyzstan and Tajikistan.

In June 2001, Uzbekistan signed the UN protocol against human trafficking. In subsequence, the government of Uzbekistan passed a law on 29 August 2001 (Law No. N 254-II), which imposed tougher sentences for crimes that have direct relevance to human trafficking. However, this law failed to introduce any amendments to the country's criminal code that would allow consideration of human trafficking activity as an autonomous crime whose definition would reflect that included in the protocol. Uzbekistan announced the ratification of the protocol in 2003, but this ratification of the document contained a number of reservations referring to its already existing laws covering the prosecution of organized crime and the confiscation of criminal incomes. As a result, despite the theoretical legal possibility of confiscating assets obtained from criminal acts in Uzbekistan, in practice such confiscations are not carried out.

Kazakhstan is planning to ratify the UNTOC Convention and to sign its supplementary protocol by the end of 2005. In October 2004, the necessary amendments to Kazakhstan's current criminal legislation were submitted to the parliament. The amendments included:

- Incorporating the definition of human trafficking as a separate article in the penal code of Kazakhstan;

- Sentencing traffickers to no less than eight years of imprisonment;

- Confiscating traffickers' assets that were acquired as a result of activities directly or indirectly related to their trafficking activities;

- Protecting trafficking victims from various threats during the investigation, trial, and after sentencing;

- Providing rehabilitation and reintegration assistance to trafficking victims by government bodies and local executive bodies in cooperation with NGOs and IGOs;

- Protecting trafficking victims who serve as witnesses from immediate deportation and/or charges for their illegal stay in the country, and giving them the right to stay in-country legally at least for the duration of their testimony in court.

To date, these amendments have not yet been passed.

Currently, certain articles included in the penal codes of Kazakhstan, Kyrgyzstan, Tajikistan, and Uzbekistan can be invoked in the prosecution of crimes involving traf- 
ficking (in Kyrgyzstan and Tajikistan), or at least separate stages of the trafficking process. In Kazakhstan and Uzbekistan - the countries which have not passed laws allowing prosecution of trafficking as autonomous crime - not all of the interconnected acts mentioned in the UN protocol as being correlated with the crime of human trafficking can be regarded as illegal under the law. For instance, Article 128 of the Penal Code of Kazakhstan and Article 135 of the Criminal Code of Uzbekistan deal with the "recruitment of persons for the purposes of sexual or other exploitation committed by using deception." Clearly, this is an act that is often part of the larger crime of human trafficking. Yet these articles address only the act of recruitment, and require proof of intent to deceive, the fact of which is very difficult to argue in court. Therefore, recruiters often escape responsibility, and transporters or exploiters cannot be charged at all under this article, unless it can be proven that they were committing the act of transportation for the purpose of "illegal limitation of a person's freedom," which is criminalized in other articles of the penal codes.

In Kyrgyzstan and Tajikistan, the articles that allow prosecution of human trafficking as an autonomous crime contain all the elements of the definition of trafficking in persons as it is set out in the UN protocol. However, investigators and prosecutors often try to avoid prosecution of traffickers under these articles, and instead choose to initiate criminal investigations under other articles that do not require such a complicated procedure of gathering evidence of all the different stages of the crime of trafficking, from recruitment to exploitation. Practically all of the noted methods of exploitation and facilitation of dependency are illegal according to the Kazakh, Kyrgyz, Tajik, and Uzbek criminal codes. These include such crimes as "selling or buying a child" (specified as a crime in Kazakhstan and Tajikistan only), "death threats and use of force," "abandonment in a dangerous situation," rape, "satisfaction of a sexual urge in an unnatural way using force," forcing a woman to consent to sexual intercourse, intercourse with or seduction of a minor under the age of sixteen, extraction of organs and human tissue, kidnapping of a person, fraud, and abuse of a position of power or vulnerability.

In addition, other general criminal acts committed against victims of trafficking during the trafficking process can also be prosecuted under the criminal codes of Central Asian countries. These crimes include:

- Causing physical harm and injuries of varying degrees of severity;

- Murder or causing a suicide;

- Coercing a woman to have an abortion;

- Involving a minor in antisocial behavior;

- Coercion of a woman to enter into marriage or hindering her from entering into marriage;

- Intentional harm or destruction of assets;

- Accepting and giving bribes;

- Abetting in the process of bribery;

- Production, use, or distribution of forged documents, stamps, or forms. 
As a result, despite the absence of the definition of human trafficking as an autonomous crime in Kazakh and Uzbek legislation, it appears that the existing legislation in Central Asia offers a broad base for the law enforcement authorities to prosecute the crime of trafficking in its entirety and to convict traffickers. In practice, however, the necessity to invoke a large number of different laws in order to bring charges against traffickers complicates the prosecution of the crime of human trafficking in its entirety. As a result, it is only possible to convict a portion of traffickers, and only for a portion of the acts they have committed, leaving the majority of offenders - and particularly the organizers of the trafficking process - to go free.

At the initial stage of the trafficking process - recruitment - the offender committing the act of recruitment can theoretically be charged with recruitment for the purposes of exploitation. In practice, in order for a person to be charged for this crime, the prosecution must provide proof that the fact of recruitment - which can consist of active dissemination of information about alleged lucrative employment opportunities abroad, or offering services for the organization of departure - was committed with the goal of exploiting the recruited individuals. Considering that the fact of exploitation usually occurs in the country of destination, and thus outside the legal jurisdiction of the country of origin, it is extremely difficult to obtain sufficient evidence of exploitation to obtain a conviction.

Moreover, the necessity to wait for the recruited individuals to be exploited in the country of destination in order to have evidence to prosecute the crime of recruitment involves a high risk of victimization of the recruited individuals and does not guarantee their release, even if the recruiter is charged and convicted in the country of origin. Also, the recruiter can use the gap in time between the moments of recruitment and exploitation to escape the country or hide from the authorities.

Another problem emerges due to the absence of a legal definition of the term "exploitation" in the criminal codes of Kazakhstan, Tajikistan, and Uzbekistan. As a result, the term is subject to the individual interpretation of a judge, and thus can be construed in divergence from the minimal standards dictated by the UN protocol. Cases have been recorded where the fact of sexual exploitation was used to acquit the offenders, when victims confessed that they were aware that they might have to engage in prostitution as part of the transportation or employment arrangement. The fact that a victim had no choice but to submit to the conditions of exploitation was not considered. Similarly, in cases of trafficking for labor exploitation, the fact that victims left the country voluntarily has been used as evidence of consent to future exploitation.

Another problem in convicting traffickers emerges when the prosecution must prove the existence of a relationship between the recruiter and exploiter, and show that they have acted on an agreement to recruit and exploit the victim - in essence, the prosecutor must prove the existence of a criminal network. If it cannot be shown that such an agreement was made between the parties, then it is impossible to argue that the goal of recruitment was exploitation. Proving such interdependency is difficult even in cases of in-country trafficking. When the nature of the crime is transnational, requiring the collection of evidence outside of the jurisdiction of Central Asian countries - assuming 
that the victim was able to return back home-victim and witness testimonies often become the only proof that exploitation occurred.

As a result, many criminal cases initiated under the articles punishing human trafficking (in Kyrgyzstan and Tajikistan) and recruitment for the purpose of exploitation (in Kazakhstan and Tajikistan) are either dismissed or closed during investigation for lack of sufficient evidence. The cases that have made it to court and were tried and convicted often resulted in lighter sentences, if not in outright amnesties, in which case the recruiter was freed directly from the courtroom and was able to continue his or her criminal activity. Hence, it is not surprising that investigators either try to avoid bringing charges under articles against "trafficking in persons" completely, or try to strengthen the accusation by bringing charges on other articles in order to raise the likelihood of conviction in court.

Convictions of traffickers on charges of kidnapping are also very rare, because victims of trafficking are not usually kidnapped. Human trafficking is a well-organized activity in Central Asia and, thanks to the convincing work of recruiters, the majority of the trafficking victims make a decision to travel abroad for work independently, without physical coercion.

Articles punishing the illegal detention of an individual become relevant only after the victim has been recruited, and the traffickers must ensure that the victim is kept in conditions that he or she cannot escape. Thus, these articles can be applied in cases where victims are forcefully kept at the place of exploitation or transported there by force. Yet, once again, the forced transportation or detention of the victim occurs rarely in the country of origin, and forced transportation or detention of the victim in the countries of transit or destination is often outside of the jurisdiction of the Central Asian states. To be sure, this article is applied in cases of internal trafficking, but courts often interpret the term "illegal detention of an individual" to mean physical limitation of a person's ability to move (keeping the person locked up, beating the person, limiting his or her connection with the outside world, etc.). Such an interpretation ignores other types of psychological or economic manipulation that traffickers often rely on to facilitate victims' obedience without necessarily locking them up. Examples of such psychological and economic manipulation include debt-bondage, blackmail, threats, etc.

In cases of human trafficking for sexual exploitation, articles against brothel-keeping and pimping are used. These articles are best applied only in cases of in-country trafficking, where the exploiter is present in the country of origin and derives direct profit from the exploitation of prostitution of victims of trafficking. In order to gain a conviction under this article, it is necessary to present evidence that a trafficker keeps a brothel and receives revenue from operating the brothel. This means that it is impossible to use this article to prosecute cases of transnational trafficking.

Considering that one or several criminal groups have to cooperate closely in order to successfully execute the crime of human trafficking, prosecution of traffickers is possible under any one of the articles mentioned against the qualified crimes that call for harsher sentences for the perpetration of the act by an organized criminal group. However, proving that a criminal agreement exists, verifying the organization of a trafficking network, and tracing the relationships between the network's actors are very diffi- 
cult tasks, especially in cases where different stages of trafficking occur in different jurisdictions.

Other shortcomings of the criminal law system that complicate the prosecution and prevention of human trafficking are the lack of a proper mechanism for the protection of victims and witnesses in court or during investigation, and the absence of any robust legal foundations for victims to seek compensation for moral harm or physical and material damages. This discourages the already reluctant victims of human trafficking from reporting their cases to the police and initiating proceedings against their traffickers.

The legislation of the countries under consideration in this essay contains a number of articles that criminalize acts committed by victims of human trafficking as a result of their situation of dependency on traffickers. One such example is Article 190 in the Code of Administrative Misdemeanors in Uzbekistan, which deals with prostitution. Persons that are arrested on prostitution charges are subject to fines and, in cases of multiple convictions, the amount of the fine increases. Considering that neither the administrative nor the criminal code of Uzbekistan criminalize the acts of persuading or coercing a person to engage in prostitution, the exploiter risks nothing in forcing a victim to engage in prostitution, because even if the victim is arrested for the provision of sexual services, it is the victim and not the person who coerced her into prostitution who bears the responsibility for the act. On the other hand, the victim is discouraged from seeking assistance from law enforcement authorities to protect her from the exploiter's actions out of fear of prosecution.

In Central Asia, victims of human trafficking can be prosecuted for the following offenses:

- Spreading a venereal disease;

- Illegal crossing of state borders;

- Using forged documents.

In practice, when victims are charged with the violations described above, considerations of the particularities and dependencies inherent to the situation of human trafficking are not taken into account. Thus, the facts that a victim was forced to commit an illegal act or that she was deceived about the consequences of her voluntary offense are not considered.

Paradoxically, however, a victim of human trafficking who is being prosecuted for certain offenses has greater protection and guarantees of her legal rights during the hearing of the case than a victim involved in a trial as a plaintiff or a witness. This apparent contradiction is explained by the fact that following the accepted standards of conducting criminal trials dictates that the right to protection must be guaranteed for each person suspected or accused of committing a criminal act. Guarantees of protection for plaintiffs are expected to follow from the work of investigative services and the court. The legal right to protection for all parties involved in a court action is guaranteed by the codes of criminal law procedures, which state that the honor and dignity of all parties involved in the criminal process must be upheld through the state protection of the parties' rights and freedoms. Yet special emphasis is placed on the protection of 
the rights of the accused, implying that victims' rights are somehow automatically protected through the fact of government prosecution of the crime. This means that first the investigator and then the prosecutor will act to protect and uphold the rights of the victim. However, practice shows that the mixture of the functions of prosecuting traffickers and protecting victims often interferes with the observation of the adversarial principle inherent in a criminal trial. Moreover, both the investigator and the prosecutor are so fully focused on proving the case that they often lack the time or opportunity to ensure that victims or witnesses are provided with adequate protection.

Moreover, when victims of human trafficking in Central Asian states report their cases to the police, the latter often view the victim as a criminal for having violated the border crossing regime or the immigration laws of the country of destination. Or they may view them as having participated in illegal prostitution abroad, but not as a victim of a transnational organized crime. Even when a criminal case is initiated, the police and other law enforcement agencies are often unable to collect necessary evidence due to their insufficient experience in investigating trafficking cases and their insufficient or nonexistent cooperation with law enforcement agencies in the countries of transit and destination. Thus, victims that are trafficked from one country to another within Central Asia, or who return to the region from abroad, fear recriminations from either traffickers, border guards, customs agents, or law enforcement officers, and as a result have little faith in the ability of the law enforcement system to protect them and bring the traffickers to justice.

In recent years, when local police apprehended foreign citizens that were trafficked to Kazakhstan from neighboring countries, they immediately deported them back to their country of origin as illegal migrants. Few other alternatives are available to Kazakh law enforcement agencies in treating such cases because Kazakhstan lacks clear legal procedures to allow the victims to remain in the country for the duration of the investigation and court hearing. Moreover, law enforcement agencies have no facilities, except for detention centers and jails, where the victims could safely stay before returning to their home country.

This situation has been changing slowly since 2003, when police in Kazakhstan began to bring criminal cases against traffickers who imported victims from a neighboring state to subject them to sexual exploitation in Kazakhstan. ${ }^{4}$ Approximately at the same time, law enforcement agencies in Kyrgyzstan, Tajikistan, and Uzbekistan started investigating a number of trafficking cases related to trafficking of their citizens abroad. These investigations focused almost exclusively on cases of trafficking for sexual exploitation, while labor exploitation cases were almost completely ignored.

$$
* * * * * *
$$

The brief analysis presented above is not complete by any means. I have primarily considered criminal legal procedures relevant to counter-trafficking. Meanwhile, a more comprehensive examination of the issues connected with providing assistance to victims

4 In the past, the police did nothing in response to such cases. 
of human trafficking would entail a detailed analysis of laws regulating social and labor relations. To develop substantial recommendations on issues relating to the detection and prosecution of human trafficking cases, it would be necessary to review not only criminal law, but also financial, tax, and citizenship law as well. Such an extensive analysis is possible only within the framework of a larger research project on jurisprudence - work I intend to continue in the future - and not in the context of a brief article such as this.

As for the IOM and the current legal framework for the regulation of efforts to counter human trafficking, the IOM always includes a legal component in its projects, participating in the development of national legislation through the organization of training programs and seminars for law enforcement personnel and lawyers. These events take place under the rubric of a currently active IOM project on counter-trafficking efforts in Central Asia. In the future, the IOM plans to continue organizing such events.

A crucial next step is to attract the attention of lawyers and other relevant counterparts from the countries of destination in order to develop a foundation for future cooperation on the harmonization of legislation between the countries of origin, transit, and destination, which would facilitate better and more inclusive prosecution of all actors involved in the criminal networks that conduct human trafficking. This would also ensure better protection of the rights and lawful interests of victims of trafficking at every stage of this transnational crime. 